\title{
Apontamentos críticos para $o$ desenvolvimento da vigilância civil da saúde
}

\section{| ${ }^{1}$ Gil Sevalho I}

Resumo: Apresentam-se, em um ensaio crítico, a ideia e os fundamentos da vigilância civil da saúde. Trata-se de proposta elaborada por Victor Valla na década de 1990, que incorpora à vigilância em saúde a participação da população por meio da educação popular de Paulo Freire. Com o aporte de recursos da Antropologia Interpretativa e da História Nova, faz-se um contraponto entre a vigilância em saúde tradicional, modelada pela vigilância epidemiológica, e a vigilância civil da saúde. Evidenciam-se, então, permanências culturais marcantes na prática da vigilância em saúde desenvolvida hegemonicamente no Brasil. A prerrogativa de cientificidade, que leva à subordinação ao modelo clínico biomédico, a vinculação política à ideia de segurança social e o critério imperativo de urgência, características da vigilância em saúde tradicional, bloqueiam ou dificultam a participação popular. Ao final, vinculase a vigilância civil da saúde à epistemologia do sul de Boaventura de Sousa Santos. O desenvolvimento da vigilância civil da saúde, que incorpora a participação popular à vigilância em saúde, vem ao encontro das propostas historicamente inscritas na concepção e na evolução da saúde coletiva e do SUS.

Palavras-chave: vigilância em saúde; vigilância civil da saúde; educação popular e saúde.

\author{
1 Escola Nacional de Saúde \\ Pública Sérgio Arouca, \\ Fundação Oswaldo Cruz. Rio de \\ Janeiro-RJ, Brasil (gsev@terra. \\ com.br)
}

Recebido em: 01/10/2015 Aprovado em: 22/04/2016 
$\mathrm{Na}$ Saúde Coletiva, entendida como área de conhecimento onde se desenvolvem as ideias produzidas na Reforma Sanitária, a vigilância em saúde deve se fazer com a participação da população, embora identifique-se que essa perspectiva não se concretizou com a territorialização das ações no Sistema Único de Saúde (SUS). Discute-se, neste texto, a relação da vigilância em saúde com a participação popular e reflete-se sobre a construção da vigilância civil da saúde.

A vigilância civil da saúde foi delineada pelo educador Victor Vincent Valla em meados dos anos 1990 e, no correr da experiência, agregou processos como a construção compartilhada do conhecimento e a ouvidoria coletiva. Realizada com a população, alicerçada na cultura local e na educação popular de Paulo Freire, a vigilância civil pode representar a vertente da vigilância em saúde que corporifique a participação popular e contribua para a transformação social, complementando a tradicional vigilância epidemiológica.

Em referência à História Nova, apontam-se permanências históricas que estruturam a vigilância em saúde e, culturalmente enraizadas nessa área de conhecimento, afastam sua prática da participação popular. A História Nova francesa percebe a ciência da história orientada segundo uma concepção cultural que objetiva conhecer a mudança, embora essa não seja compreendida sem que se identifiquem as permanências das quais se distingue (LE GOFF, 1990; BRAUDEL, 1992).

Entende-se, então, cultura, como Geertz (2008, p. 32-33) em sua Antropologia Interpretativa, como "conjunto de mecanismos de controle - planos, receitas, regras, instruções" que conformam "programas" que servem para "governar o comportamento". O ser humano, pensa Geertz, depende "desesperadamente" desses "mecanismos de controle, extragenéticos, fora da pele, de tais programas culturais, para ordenar seu comportamento".

A vigilância em saúde, hegemonicamente estabelecida, pode ser pensada no contexto das observações de Foucault (1987), quando na constituição histórica da modernidade é percebida a gradativa domesticação da sociedade com a instituição do poder sobre o corpo humano, alicerçada numa vigilância coercitiva dos movimentos e das aglomerações humanas, dos gestos e comportamentos. A essa domesticação alia-se uma ordem política global que impõe e legitima a injustiça social. 
Este texto é um ensaio, ou seja, um exercício "necessariamente crítico" que busca construir ideias originais sobre temas em apreciação (MOISÉS, 2004, p. 147). Segundo Adorno (2008, p. 44), o ensaio "quer desencavar, com os conceitos, aquilo que não cabe em conceitos", ou revelar o que contraditoriamente enreda os conceitos numa pretensa objetividade. O ensaio rompe com a ortodoxia acadêmica que recusa, em nome da formalidade, experimentar abordagens que podem trazer novas formas de pensamento. Entende-se que "para saber a estrutura profunda de uma prática institucional, temos que interrogar sobre o que ela proíbe" (LARROSA, 2003, p. 102).

\section{Fundamentos históricos críticos da vigilância em saúde}

Romero e Troncoso (1981) relacionam uma vigilância de doentes e suspeitos com a quarentena nascida durante a peste negra da Idade Média, no século XIV, na Europa, para sanear o tráfego marítimo.

A estatística, enquanto medida do Estado, e, posteriormente, a estatística médica nasceram nos séculos XVII e XVIII para contar indivíduos sadios e produtivos (ALMEIDA FILHO, 1989). Surgiram para medir o poder do Estado, quando grandes populações fortaleciam o contingente militar e a capacidade produtiva numa época em que as tecnologias bélicas e de produção de riquezas eram precárias.

Nesse contexto, formou-se, no século XVIII, uma medicina social, envolvendo a polícia médica alemã, uma medicina de Estado que normalizou a prática e a organização médicas, a medicina urbana francesa, que saneou as cidades, e a medicina da força de trabalho inglesa, que controlou os pobres e a força de trabalho industrial (FOUCAULT, 1979). A cidade, os trabalhadores, os pobres foram alvos da medicina social voltada para o controle dos miasmas causadores das doenças.

Sevalho (1993), apoiando-se em Corbin (1987, p. 194, 183), identifica uma estratégia saneadora e terapêutica guiada pela percepção olfativa, que, incitada pelo imaginário coletivo, caminhou para uma desodorização social diferenciada. A definição do "pertencimento social" perseguiu os "odores da miséria, a descobrir o fedor do pobre e de sua toca”.

Prática sistemática contínua de coleta, análise de dados e distribuição de informaçôes, a vigilância inspirou-se, segundo Langmuir (1976), nos trabalhos de William Farr, o registrador de doenças da Inglaterra e Gales do século XIX. Os dados produzidos por Farr, defensor da Teoria Miasmática, possibilitaram a John 
Snow (SNOW, 1990), o fundador da epidemiologia moderna, investigar, em meados do século XIX, antes do advento da microbiologia, a "maneira de transmissão do cólera” relacionando a doença à contaminação da água e ao contágio.

Já no contexto de uma epidemiologia dos modos de transmissão, uma vigilância focada no controle e isolamento de contatos, suspeitos e portadores de doenças transmissíveis contribuiu para a empresa colonialista que, nos países agrário-exportadores, saneou as áreas produtoras de matéria-prima para o mundo capitalista industrializado no início do século XX.

Essa vigilância é ancorada na ordem simbólica das representações belicistas da guerra contra os micróbios, movida pela microbiologia fundada no último terço do século XIX (SEVALHO, 2000). Para Romero e Troncoso (1981, p. 4), não é casual o fato de "famosos" epidemiologistas do começo dos anos 1900, como Guateras, Carter e Reed, serem oficiais de alta patente do exército dos Estados Unidos. Termos como "vigilância", "controle", "evento sentinela" e "campanha" pertencem a esse cenário de inspiração militar.

A vigilância de doentes e suspeitos compõe uma política sanitária autoritária, persecutória e punitiva (SEVALHO, 2000, p. 111). Ilustra essa prática o caso de uma cozinheira que, no início do século XX, foi identificada como portadora assintomática de febre tifoide pelo Departamento de Saúde da cidade de Nova Iorque. Segundo Calder (1958), a mulher, apelidada de "Typhoid Mary", foi perseguida até ser encontrada em 1907 vivendo sob nome falso como uma criminosa, tendo depois ganhado um emprego no Departamento de Saúde, para que fosse vigiada até o fim da vida.

Após a Segunda Guerra Mundial, a introdução da malária nos EUA por soldados que retornavam da África e regiōes do Mediterrâneo e Pacífico fez com que a vigilância ganhasse importância (THACKER; BERKELMAN, 1988). Segundo Souza et al. (1992), a era da Guerra Fria estabeleceu entre os norteamericanos o medo de uma guerra biológica.

Ataques biológicos podem ser percebidos desde a Idade Média. O catapultamento de cadáveres contaminados pela peste por sobre muralhas de castelos medievais sitiados, na vigência das constituições pestilenciais de origem miasmática, pode corresponder ao envio de cartas contaminadas pelo agente do antraz como ato de guerra ou terrorismo, na atualidade da epidemiologia dos fatores de risco. 
O termo "vigilância" foi primeiro utilizado nos EUA no controle da poliomielite, por ocasião do cutter incident na década de 1950, e consagrou-se internacionalmente na saúde pública a partir do trabalho de Karel Raska, no começo dos anos 1960 na Tchecoslováquia (LANGMUIR, 1971).

$\mathrm{O}$ "cutter incident" refere-se à ocorrência de poliomielite vacinal entre crianças norteamericanas após uma primeira vacinação em massa contra a doença. Os lotes de vacinas envolvidos foram produzidos por Cutter Laboratories, da Califórnia, e liberados para uso em atendimento a pressóes da imprensa e da National Foundation for Infantile Paralysis. Brandt (1978) classifica criticamente o evento como o maior "ensaio clínico" já realizado, desde que as vacinas não haviam sido devidamente testadas antes de sua aplicação. O saldo do incidente pode ter chegado a 260 casos de poliomielite vacinal e 11 óbitos (NATHANSON; LANGMUIR, 1963; BRANDT, 1978).

Langmuir $(1971,1976)$ aponta que os anos 1950 apresentaram uma nova versão de vigilância focada em doenças específicas, caracteristicamente uma vigilância centrada no comportamento da doença e não de indivíduos doentes e suspeitos.

A adjetivação "epidemiológica" para a vigilância surgiu em meados dos anos 1960, associada à unificação da expressão promovida pela Organização Mundial da Saúde (THACKER; BERKELMAN, 1988). Thacker e Berkelman (1988, p. 164) propuseram a expressão "vigilância em saúde pública", definindo o processo como "coleta, análise e interpretação sistemáticas e permanentes de dados sobre saúde essenciais ao planejamento, implementação e avaliação de práticas em saúde pública, integradas à pronta disseminação dos dados a todos aqueles que devem conhecê-los".

Langmuir (1971, p. 12) entendia a vigilância como uma "inteligência epidemiológica" caracterizada como processo centralizado de coleta, manipulação e difusão de dados e interpretações, que não abrangia a execução das medidas de controle. O debate desencadeado pela 21 a Assembleia da OMS, de 1968, resultou numa vigilância hierarquizada em níveis nacionais e internacionais, que, referenciando-se à capacidade dos serviços, passou a incluir ações de controle (FOSSAERT; LLOPIS; TIGRE, 1974). Foram incorporadas doenças não infecciosas, anomalias congênitas, reações aos medicamentos, problemas nutricionais e riscos ambientais e ocupacionais (OMS, 1968). 
A reboque da Epidemiologia, o campo da Vigilância Epidemiológica abrigou, a partir das décadas de 1960 e 70, os eventos mórbidos surgidos no século XX, incluindo os agravos ligados às violências e ao uso das modernas tecnologias médicas, já na perspectiva da epidemiologia dos fatores de risco. Embora o desenvolvimento da vigilância tenha procurado estabelecê-la como procedimento técnico não repressivo, a incorporação da dimensão cultural à análise histórica mostra a permanência do caráter coercitivo nas formas de compreensão e enfrentamento da doença. Preconceitos relacionados à aids persistem e, em nome da contenção de epidemias, justificam-se ainda hoje medidas que ferem princípios éticos e atingem frontalmente as liberdades civis. Jacintho-da-Silva (2008) aponta práticas restritivas de isolamento compulsório e quarentena na vigência das atuais epidemias de infecções emergentes, especialmente da síndrome respiratória aguda grave (srag), em países da Ásia, Europa e América do Norte.

No Brasil, conformada como um sistema de “informação para ação” orientado pelo modelo descrito, a vigilância epidemiológica volta-se predominantemente para o controle das doenças infecciosas e transmissíveis, configurando uma "vigilância de casos" submetida logicamente ao modelo clínico biomédico que tem sua expressão exemplar nos Centros de Controle de Doenças (CDC) norteamericanos. Guardando correspondência com os princípios estruturais de universalidade, equidade, integralidade e participação da população, procurouse ampliar a abrangência da vigilância para o risco epidemiológico e surgiram no país as expressões "vigilância em saúde" (PAIM; SILVEIRA, 1972), "vigilância à saúde" (MENDES, 1993), "vigilância da saúde" (TEIXEIRA; PAIM; VILASBÔAS, 1998).

Deve-se, contudo, considerar o contexto histórico que envolve a Reforma Sanitária e a especificidade exemplar do SUS como projeto de atenção à saúde originado na luta pela redemocratização do país. O SUS foi forjado no bojo das contradições políticas que marcaram a Reforma e a opção por uma desconstrução a partir de dentro, por meio da ocupação de cargos diretivos no aparelho do Estado, prevaleceu nas décadas de 1970, 80 e 90, quando o mundo mergulhava na era da globalização do capital sob a dominação neoliberal. O neoliberalismo, aponta Harvey (2008), mais do que um modelo econômico, constitui uma visão de mundo dominante definida pela subordinação das relações sociais à ordem do 
mercado que molda, no nível global, mentes acadêmicas e políticas públicas. O

SUS e o campo da Saúde Coletiva emergem embebidos dessa complexidade, e sua história se constrói entre a resistência crítica e a acomodação.

Na década de 1970 foi criado o Sistema Nacional de Vigilância Epidemiológica (SNVE), atendendo a determinações da OMS para implantação de sistemas de vigilância nos países em desenvolvimento. O texto da Lei Orgânica da Saúde, Lei $n^{\circ} 8.080$ de 1990 , enfatiza a descentralização da vigilância epidemiológica e a define como conjunto de ações voltado para o conhecimento, a detecção ou prevenção de mudanças nos fatores determinantes e condicionantes da saúde, objetivando a recomendação e a adoção de medidas de prevenção e controle de doenças e agravos (ALBUQUERQUE; CARVALHO; LIMA, 2002).

A adoção oficial da expressão "vigilância em saúde" no lugar de "epidemiologia e controle de doenças" surgiu no texto de Portaria do Ministério da Saúde em 2004 (BRASIL, 2007, p. 23). Atualmente, permanecem estruturados o Sistema Nacional de Vigilância em Saúde e o Sistema Nacional de Vigilância Sanitária, o último criado em 1999 juntamente com a Agência Nacional de Vigilância Sanitária.

Apesar da pretensão oficial de união das vigilâncias epidemiológica e sanitária, ambas mantêm especificidades técnicas e culturas institucionais próprias. Entre uma racionalidade "técnico-sanitária fundamentada na clínica e na epidemiologia" e uma "racionalidade político-jurídica" focada na regulação de produção e consumo de bens e serviços e no controle sanitário de portos, aeroportos e fronteiras (ARREAZA; MORAES, 2010, p. 2216), as vigilâncias epidemiológica e sanitária, no Brasil, atuam juntas apenas em situações episódicas.

$\mathrm{Na}$ descentralização dos serviços no SUS, criaram-se, sequencialmente, "distritos sanitários", "sistemas municipais de saúde", "microrregiões de saúde" (TEIXEIRA, 2002) e, nessa perspectiva, as ações de vigilância constituíram um processo de localização espacial em busca da aproximação dos eventos abordados.

Com ênfase na perspectiva local, propõe-se intervir nos determinantes das condições de saúde (TEIXEIRA, 2002), sob a lógica da territorialização dos serviços (MONKEN; BARCELLOS, 2005; FARIA; BERTOLOZZI, 2009). A territorialização da vigilância em saúde requer sua integração à Atenção Básica e à Estratégia Saúde da Família (ESF), desde que esta se tornou a abordagem privilegiada pelo SUS. 

o discurso oficial na Saúde Coletiva. Território, então, é espaço existencial que transcende a dimensão física, onde constroem-se resistências populares e solidariedade contrapondo-se à alienação promovida pelo capital globalizado sob a liderança das corporações transnacionais. A vigilância em saúde deve ser realizada com a participação da comunidade, em ajuste contínuo com a realidade que se apresenta a partir do convívio com a população, na mutualidade da troca permanente de conhecimentos e saberes técnico-científicos e populares.

Avalia-se, no entanto, que dominam nos serviços as intervençôes verticais baseadas nas práticas tradicionais de notificação, registro e investigação de casos de doenças infecciosas, persistindo a consequente desarticulação em relação à Atenção Básica e à ESF (RODRIGUES; FRACOLLI; OLIVEIRA, 2001; LEITE; ASSIS; CERQUEIRA, 2003; SANTOS; MELO, 2008; FARIA; BERTOLOZZI, 2010). Revisões e pesquisas empíricas, como as de Faria e Bertolozzi (2009, 2010), apontam que a prática da vigilância em saúde permanece afastada dos movimentos sociais e das redes populares de produção de saúde, não se concretizando a preconizada participação da população nas ações.

A realidade evidencia a distância entre o tom crítico do discurso oficial e a dominação das práticas conservadoras na área da vigilância em saúde.

\section{A vigilância civil da saúde como perspectiva socialmente transformadora fundamentada na educação popular}

A ideia de uma "vigilância civil da saúde" foi criada por Victor Vincent Valla (1937-2009), que pensou o conceito como uma "monitoração civil” da saúde (VALLA, 1993b). Percebendo "a necessidade de a sociedade civil de caráter popular criar um banco de dados alternativo e desenvolver uma monitoração dos agravos à saúde", Valla (1993b, p. 106) pretendeu realizar "uma epidemiologia do cotidiano, desenvolvida pelos setores populares juntamente com profissionais interessados na proposta".

Consideram-se as "condições de vida", que apontam para uma realidade social e economicamente determinada, e as "experiências de vida", que exprimem a forma de "apropriação da realidade, e as possibilidades de ação sobre ela", revelando "o universo cotidiano, o conhecimento e a visão de mundo dos grupos populares" (OLIVEIRA; VALLA, 2001, p. 80). Valla (1993b, p. 106) pensou 
a vigilância civil como união das propostas da "epidemiologia comunitária" de Tognoni (1991, 1997) e do "diagnóstico participativo", conjugadas em uma "investigação alternativa” trabalhada por "profissionais de saúde e educação com os setores organizados e populares da sociedade civil".

A epidemiologia comunitária foi trabalhada por Tognoni (1997) no Equador, na primeira metade da década de 1990, envolvendo ativamente o pessoal auxiliar e a população desde o diagnóstico da situação de saúde. $\mathrm{O}$ autor a reconhece como "um instrumento de autoconsciência da comunidade" que objetiva "contar a história das enfermidades na comunidade para que esta possa se livrar delas", fazendo crescer "sua capacidade de organizar-se de uma forma consciente" (TOGNONI, 1991, p. 4). Os informes epidemiológicos são, em linguagem, conteúdo e distribuição, acessíveis a todos e não somente ao pessoal de saúde, integrando a cultura local.

Para Eduardo Stotz (STOTZ, 2009, p. 462), a vigilância civil formulada por Valla assenta-se na construção de uma "observação participativa" que, reunindo educação, como "finalidade", e saúde, como "meio", procura dar "consistência técnica" às reivindicaçôes das organizações civis de caráter popular e possibilitar aos planejadores de saúde adequar os serviços às necessidades da população, viabilizando "propostas oriundas do movimento social".

A vigilância civil da saúde tem embasamento teórico e prático vinculado aos campos da vigilância e da educação em saúde, alicerçado na educação popular de Paulo Freire. Segundo Stotz (2009, p. 461), a educação popular de Paulo Freire constitui "método de construção de uma nova consciência social" implicando "solidariamente educadores e educandos num processo educativo e político", de modo que o homem do povo possa "assumir-se enquanto sujeito da transformação de sua vida e, portanto, da sociedade que, em parte", a determina.

Para Freire (1996, p. 99), "do ponto de vista dos interesses dominantes", a educação é "uma prática imobilizadora e ocultadora de verdades", própria de um contexto em que "os avanços técnicos" só são realizados se compreendidos de forma neutra. A educação popular de Freire (1977) é captação dos dados da realidade por meio da transformação da curiosidade ingênua em curiosidade crítica que deve se estabelecer contrariamente à dominação, como prática que se reconhece em seu inacabamento, intencionalidade e concepção ideológica a favor da mobilização socialmente transformadora. 
A vigilância civil da saúde envolve uma epidemiologia que, enquanto "investigação participativa”, se coloca, em teoria e prática, ao lado da população (VALLA, 1993b, p. 106). A partir da experiência da população, unem-se os saberes dos técnicos e profissionais aos saberes populares e problematiza-se à luz das condições de vida e do conflito social.

Contam Vasconcelos (2001) e Stotz (2005) que os movimentos de educação popular na saúde surgiram na resistência ao regime militar na década de 1970, quando profissionais de saúde rumaram para periferias urbanas e áreas rurais buscando alternativas para a rotina das práticas mercantilizadas e mantenedoras do sistema de relações sociais injustas. Grande parte dessas iniciativas constituiu experiências informais ligadas à Igreja Católica e não foi registrada, mas Stotz (2005), num esforço de pesquisa histórica, descreve aquelas marcantes: a experiência de Porto Nacional e do Meio Grito, em Goiás; a experiência de Cabuçu, em Nova Iguaçu, Rio de Janeiro; e o Movimento da Zona Leste, na cidade de São Paulo. Essas experiências tiveram em comum a vinculação com as classes populares no enfrentamento da ditadura militar e o posicionamento contra-hegemônico em relação às práticas comunitárias orientadas pela cientificidade biomédica.

Stotz (2005) aponta que os programas institucionais de medicina simplificada e extensão de cobertura internacionalizados pela OMS subordinam-se ao saber biomédico e servem à manutenção de relações de dominação. A participação social contextualizada na medicina comunitária dos anos 1970 e 80 visa estimular populações pobres para fazer uso dos próprios recursos para superação de sua marginalidade.

Segundo Stotz (1994), os protagonistas do movimento da Reforma Sanitária privilegiaram concepções de proteção social, cidadania e Estado modeladas pelo Welfare State, sem enfrentar analiticamente a constituição do Estado brasileiro. Assim, a participação social pensada no âmbito da Reforma inscreve-se numa ordem política compensatória e não transformadora das relações entre Estado e sociedade. Essa foi a concepção de controle social institucionalizada no arcabouço do SUS, ao nível das Conferências e Conselhos de Saúde, conformando um processo que se aproximou do Estado e se afastou dos movimentos populares.

Valla (1998, p. 32) externou, no final dos anos 1990, a preocupação de que os Conselhos de Saúde institucionalizados representavam um risco de "encurralar" 
os movimentos populares, bloqueando burocraticamente reivindicações e mudanças. Bravo e Correia (2012) reforçam esse ponto de vista ao contarem da derrota da pretensão de uma independência em relação ao Estado, nos embates travados em torno da VIII Conferência Nacional de Saúde. A opção vencedora, de uma política institucional, era entendida pelo Movimento Popular de Saúde (MOPS) como um risco de desorganização da ação popular.

No desenvolvimento da vigilância civil da saúde, por sua vez, destacam-se as abordagens de "construção compartilhada do conhecimento" e "ouvidoria coletiva", orientadas pela pesquisa participante. "Construção compartilhada do conhecimento" foi termo criado no Núcleo de Educação, Saúde e Cidadania do Departamento de Ciências Sociais da Escola Nacional de Saúde Pública (ENSP)/ Fiocruz em meados da década de 1980. Segundo Carvalho, Acioli e Stotz (2001, p. 106), a inspiração veio dos trabalhos populares realizados na Zona Leste da cidade de São Paulo e em áreas programáticas de saúde do município do Rio de Janeiro nos anos 1970 e 80, focados na reorientação das políticas públicas em favor das "classes subalternas". A abordagem é fundamentada na percepção de que "sujeitos com saberes diferentes, porém não hierarquizados, se relacionam a partir de interesses comuns" e objetiva a "conquista" pelos grupos populares de poder de intervenção nos processos que condicionam a vida (CARVALHO; ACIOLI; STOTZ, 2001, p. 101-102).

Foi uma elaboração coletiva dos pesquisadores do Centro de Estudos e Pesquisas da Leopoldina (CEPEL), entidade de caráter não governamental que atuou nas favelas da Penha, na área servida pelos trens da Leopoldina, no município do Rio de Janeiro, no período de 1988 a 2006, e teve Victor Valla como presidente (STOTZ, 2009).

A construção compartilhada do conhecimento frutifica da relação entre senso comum e ciência e partiu da constatação, no trabalho de campo, de que é necessário e possível desenvolver experiências conjuntas de troca e produção de conhecimento entre profissionais de saúde e população. Essa capacitação mútua foi, inicialmente, percebida por Valla (1993a) como construção desigual do conhecimento desigual.

Para Carvalho, Acioli e Stotz (2001), a impressão inicial foi de que a diferença de conhecimentos entre profissionais e técnicos, de um lado, e população, de outro, deveria ser resolvida realizando-se oficinas de capacitação técnica de 
educação e saúde para a comunidade. As oficinas evidenciaram criticamente a hierarquia dominante de conhecimento pautada pela transmissão unilateral de saberes, e revelaram que as necessidades da população e suas formas de enfrentamento dos problemas eram desconhecidos pelos profissionais e técnicos. O processo resultou na construção compartilhada do conhecimento, inspirada na educação popular de Paulo Freire, reunindo recursos da pesquisa-ação e da pesquisa participante.

A ouvidoria coletiva, segundo Guimarães et al. (2011, p. 291, 293), foi experimentada junto à população urbana da região da Leopoldina, que "permitiu organizar, de modo sistemático, a escuta e favoreceu o reconhecimento do saber local, construído a partir das experiências de vida das pessoas que lidam com o sofrimento, a doença eseus determinantes". Pesquisa social qualitativa, "escuta ativa da população", a abordagem "promove uma busca de informações aprofundadas sobre as condições de vida das comunidades, por meio da incorporação do olhar de atores sociais" que vivenciam a situação e "se constituem em porta-vozes dos grupos que representam".

"Concepção que amplia a visão tradicional de vigilância à saúde", trabalha com grupos de representantes de profissionais e técnicos e lideranças comunitárias que em fóruns periódicos elegem e discutem temas, sendo os resultados das discussões elaborados em plenárias. Concebidos de acordo com os "pressupostos do processo de 'construção compartilhada do conhecimento", os fóruns de ouvidoria coletiva constituem "espaços privilegiados de diálogo entre os saberes científicos e os populares" (GUIMARÃES et al., 2011, p. 293). A ouvidoria coletiva evidenciou "informaçôes e práticas participativas, tecidas pela sociedade civil, que se encontram muitas vezes invisíveis para grande parte dos profissionais de saúde e gestores", permitiu uma "releitura dos problemas de saúde" e possibilitou a "construção de novas redes participativas e atuantes" envolvendo lideranças comunitárias e religiosas na reflexão crítica sobre as políticas públicas de saúde (GUIMARÃES et al., 2011, p. 299).

Carvalho, Acioli e Stotz (2001) e Guimarães et al. (2011) apontam que a construção compartilhada do conhecimento e a ouvidoria coletiva foram efetivamente usadas na década de 1990 pelo grupo de Victor Valla e Eduardo Stotz na região da Leopoldina, na atuação do CEPEL. E uma experiência de ouvidoria coletiva foi desenvolvida por Carla Moura Lima (LIMA et al., 2011) na 
região de Itaboraí, no Estado do Rio de Janeiro, de 2008 a 2011, incorporando o

objetivo de capacitar agentes comunitários de saúde nessa abordagem.

A expressão "vigilância civil da saúde" é identificada no artigo de Guimarães et al. (2011, p. 292), referenciada à pesquisa "Vigilância Civil da Saúde: uma proposta de Ouvidoria Coletiva na AP 3.1, Rio de Janeiro", iniciada em 2003. A primeira menção da expressão data da pesquisa "Redes sociais e vigilância civil da saúde no nível local”, que teve início em 2001, coordenada por Eduardo Stotz no Núcleo de Estudos Locais em Saúde (ELOS).

A educação popular é recomendada oficialmente, mas as práticas de educação em saúde no Brasil são tradicionalmente subordinadas ao conhecimento biomédico. Autoritárias e prescritivas, pressupõem que a população ignora, e portanto, uma transmissão de conhecimento deve partir do profissional de saúde, aquele que supostamente sabe. Focadas em doenças específicas, são definidas verticalmente para solucionar problemas sentidos pelos serviços, não pela população. Estudos como o de Gazzinelli et al. (2013) mostram que esse é o modelo de educação em saúde que prevalece no âmbito da ESF.

\section{Permanências históricas da vigilância em saúde e a vigilância civil da saúde}

A história da vigilância em saúde é cenário de consolidação de um modelo hegemônico marcado por certas características fundamentais que constituem elementos consagrados internacionalmente, porquanto reconhecidos por sua eficácia técnica. Como tal, inscrevem-se no âmbito epistemológico de uma ordem paradigmática dominante e representam marcas simbólicas, tradiçōes de determinado campo organizacional de prática e conhecimento.

Sob inspiração da história nova francesa (LE GOFF, 1990) e seguindo o ponto de vista de Geertz (2008), que entende cultura como conjunto de símbolos e significados compartilhados que serve como mecanismo de controle e ordenação do comportamento humano, identificamos, criticamente, permanências históricas que modelam epistemológica e culturalmente a vigilância em saúde: a prerrogativa de uma cientificidade universal, a vinculação política à ideia de segurança social e o critério imperativo de urgência. Tais elementos movem-se lentamente no tempo, resistem em sua interdependência estrutural e conformam um saber fazer que afasta a vigilância em saúde da participação popular. 
De acordo com a prerrogativa de cientificidade, a vigilância em saúde subordina-se ao modelo clínico de inspiração biomédica e ao discurso e utilização de protocolos de investigação próprios desse contexto, estruturandose como vigilância de "casos". A epidemiologia foi conformada como "ciência dura”, moldou-se pela generalização e pela quantificação e sempre se relacionou dificilmente com a pesquisa qualitativa, e assim é orientada a vigilância.

$\mathrm{Na}$ perspectiva dominante, o saber popular não é considerado forma legítima de conhecimento sobre a saúde. A universalização do conhecimento renega abordagens que se abrem para epistemologias críticas e emancipadoras que reconhecem o saber popular como fundamental.

A vigilância civil da saúde é monitoramento desenvolvido coletivamente com a população que permite trabalhar com situações de saúde. A vigilância em saúde, estruturada como vigilância epidemiológica, é vigilância de Estado, controle social exercido sobre a população. Vinculada à segurança de Estado, assume postura prescritiva e autoritária, ligando sua fundamentação teórica e operacional a termos de inspiração militar contextualizados na "guerra" contra os agentes microbianos. Nesse contexto, o critério de urgência impõe a necessidade de resposta imediata. Prescrevem-se e executam-se açōes autoritárias, verticais e indiscutíveis porquanto absolutamente prioritárias para a defesa da sociedade diante do risco de epidemias e abalo da ordem social.

Victor Valla (VALLA, 1993a, p. 96) revelou a "ditadura da urgência" nas ações dos serviços de saúde como justificativa para a realização de intervençôes que, culpabilizando as vítimas, assentam-se na transferência de responsabilidades do Estado para a população. A utilização da comunidade, então, é um processo de dominação que nada tem a ver com a legítima participação popular nas políticas e ações de saúde.

Quando incorporada às tradicionais ações de vigilância, a população funciona tão somente como fonte de notificação alternativa de casos de doenças por meio dos chamados "rumores" que chegam aos serviços de saúde. A ditadura da urgência, reforçada porque os serviços de saúde raramente conseguem se antecipar aos fatos, consolida a hegemonia dos profissionais e não permite diálogo com a população. As conhecidas qualificações da vigilância epidemiológica como "inteligência epidemiológica" (LANGMUIR, 1971, p. 12) "braço armado" da Epidemiologia (ROMERO; TRONCOSO, 1981, p. 21) e "informação para ação" evidenciam as permanências históricas identificadas. 
Os elementos descritos representam marcas culturais do campo de conhecimento da vigilância em saúde. Tratar a questão em sua dimensão simbólica permite transcender a razão exclusivamente técnica. Nessa abordagem assumem-se riscos, mas examina-se o contexto sob uma luz alternativa alçada à complexidade. E na experiência interdisciplinar, lembremos de Morin (1991, p. 141), ao afirmar que é bom que os conceitos viajem "clandestinamente" sem a detecção pelos "fiscais da alfândega".

Os serviços de vigilância estruturam-se segundo pressupostos, subjetivados e compartilhados pelos pares, que, por seu valor prático e sua conformação como sistema de poder e controle, constituem um modo de pensar e operar. Esclareçase, procurando ser fiel às ideias de Geertz (2008), que a cultura não é, em si, o poder. Cultura é o contexto particular que permite às características apontadas fazerem sentido.

Para Geertz (2008, p. 4, 33), "o homem é um animal amarrado a teias de significados que ele mesmo teceu”, e são essas teias e sua análise que constituem a cultura. A cultura é condição essencial de existência, é "totalidade acumulada de padrōes" que constituem "sistemas organizados de símbolos significantes".

A vigilância em saúde, como é interpretada neste ensaio, realiza-se também como ação simbólica inscrita em determinado contexto. As permanências históricas apontadas dificultam e mesmo, em determinadas circunstâncias, impedem a incorporação das redes populares de produção de saúde e dos movimentos sociais não institucionalizados nas ações de vigilância em saúde, obstaculizando reivindicações e conquistas populares.

\section{Considerações finais}

Pontos de vista contra-hegemônicos em relação ao neoliberalismo liderado pelos EUA e Europa, desenvolveram-se, na década de 1990, no cenário do conhecimento. Com notável semelhança na análise de contexto e proposições, devem ser consideradas a vigilância civil de Valla (1993b), no âmbito da Saúde Coletiva brasileira, a epidemiologia comunitária de Gianni Tognoni (TOGNONI, 1991, 1997) e o monitoramento participativo de Jaime Breilh (BREILH, 1997, 2003), na perspectiva da epidemiologia crítica latino-americana.

Breilh (2003, p. 938, 940) propõe "compreender o cenário histórico" com o sentido de perguntar "se o que queremos fazer é vigiar passivamente 
os indicadores da derrota dos direitos" da população sob o neoliberalismo ou orientar as ações de monitoramento da saúde "até um processo participativo de empoderamento de nossas coletividades". A "vigilância convencional de 'fatores de adoecimento", aponta Breilh, é "um instrumento funcional ao poder” e o monitoramento participativo é caracterizado como "um instrumento de poder coletivo para a prevenção profunda", um "monitoramento de determinantes da saúde" voltado para a transformação social. Para o autor, "não tem sentido seguir com essa inócua e reducionista vigilância epidemiológica que se brinda ingenuamente em vigiar, sem questionar".

Ação de resistência, de agentes comprometidos com a transformação social, a vigilância civil da saúde pensada por Victor Valla tem, especialmente, a relevante fundamentação, teórica e prática, na educação popular de Paulo Freire.

Com dimensão epistemológica ampla, inscreve-se nesse panorama crítico a Epistemologia do Sul de Boaventura de Sousa Santos (SOUSA SANTOS, 2007; SOUSA SANTOS; MENESES, 2010), para quem as ciências sociais dominantes, produzidas no Norte, estabeleceram uma relação abissal entre regulação e emancipação que torna invisíveis os conhecimentos produzidos fora dos EUA e Europa. Admitindo a permanência de uma colonialidade do saber que promove um epistemicídio, a proposta de Sousa Santos (2010) tem como fundamento a consideração científica do saber popular produzido nas experiências sociais locais.

Carlos Rodrigues Brandão (2007, p. 35), conhecedor da obra freireana, identifica aproximações importantes entre a Epistemologia do Sul de Boaventura de Sousa Santos e a educação popular de Paulo Freire, evidentes nas perspectivas epistemológicas de complexidade e nas propostas críticas quanto à relação entre a "ciência da norma culta" e o saber popular. Adotando-se o ponto de vista epistemológico de Sousa Santos, identifica-se a vigilância em saúde tradicional como perspectiva de regulação e a vigilância civil da saúde como emancipatória.

Críticas ao modelo dominante de vigilância em saúde podem ser relacionadas às questôes apontadas neste ensaio. Uma investigação qualitativa de Omidian, Tehounge e Monger (2014), realizada enquanto a doença pelo vírus ebola se alastrava em região da África marcada pela violência civil, pobreza e exclusão social, aponta a realização de ações verticais de controle quando já se apresentavam riscos para os países ricos diante do atraso da mobilização das autoridades sanitárias internacionais. $\mathrm{O}$ estudo revela que o desrespeito para com a população e seus costumes prejudicou a contenção da epidemia. A 
separação entre as vítimas e suas famílias, que não viam mais os doentes cujos corpos eram incinerados, e o consequente impedimento de realização de rituais fúnebres enraizados na cultura local, alimentaram profunda desconfiança da parte da população em relação aos serviços de saúde.

Percebe-se que Omidian, Tehoungue e Monger (2014) descrevem uma prática de vigilância fundamentada no pressuposto da cientificidade universal do conhecimento biomédico, vinculada à ideia de segurança social e dominada pelo critério imperativo de urgência. A imperiosa ordem externa sufoca temporalidades, ritmos, valores e saberes locais.

Stotz (2009, p. 463) percebe que a "crise de compreensão", que separa profissionais das instâncias públicas de educação e saúde e pessoas das classes populares, vem da incapacidade de relativização do ponto de vista dos profissionais que previamente subjugam a população. A construção da solidariedade e da resistência à dominação vem da compreensão de que as pessoas para as quais se volta a prestação de serviços são capazes de conhecer e agir sobre sua realidade.

\section{Referências}

ADORNO, T. W. O ensaio como forma. In: . Notas de literatura I. São Paulo: Duas Cidades, 2008. p. 15-45.

AlbuQUerque, M. I. N.; CARVAlHO, E. M. F.; LiMA, L. P. Vigilância epidemiológica: conceitos e institucionalização. Revista Brasileira de Saúde Materno-Infantil, vol. 2, n. 1, p. 7-14, 2002.

ALMEIDA FILHO, N. Epidemiologia sem números: uma introdução crítica à ciência epidemiológica. Rio de Janeiro: Campus, 1989.

ARREAZA, A. L. V.; MORAES, J. C. Vigilância da saúde: fundamentos, interfaces e tendências. Ciência \& Saúde Coletiva, v. 15, n. 4, p. 2215-2228, 2010.

BRANDÃO, C. R. Entre Paulo e Boaventura: algumas aproximaçôes entre o saber e a pesquisa. Proposta, v. 31, n. 113, p. 38-48, 2007.

BRANDT, A. M. Polio, politics, publicity, and duplicity: ethical aspects in the development of the Salk vaccine. International Journal of Health Services, v. 8, n. 2, p. 257-270, 1978.

BRASIL. Conselho Nacional de Secretários de Saúde (CONASS). Vigilancia em Saúde. Brasília: CONASS, 2007.

BRAUDEL, F. Escritos sobre a história. São Paulo: Perspectiva, 1992.

BRAVO, M. I. S.; CORREIA, M. V. C. Desafios do controle social na atualidade. Serviço Social \& Sociedade, n. 109, p. 126-150, 2012. 
BREILH, J. De la vigilancia convencional al monitoreo participativo. Ciência \& Saúde Coletiva, v. 8, n. 4, p. 937-951, 2003.

. Vigilancia clásica o monitoreo estatégico en salud. In: . Nuevos conceptos y

técnicas de investigación. Quito: Ediciones del Centro de Estudios y Asesoria en Salud, 1997. p. 203-221.

CALDER, R. Medicine and man. New York: The New American Library of World Literature, 1958.

CARVAlHO, M. A. P; ACIOLI, S.; STOTZ, E. N. O processo de construção compartilhada do conhecimento: uma experiência científica do ponto de vista popular. In: VASCONCELOS, E. B. (org.). A saúde nas palavras e nos gestos: reflexóes da rede de educação popular e saúde. São Paulo: Hucitec, 2001. p. 101-114.

CORBIN, A. Saberes e odores. São Paulo: Companhia das Letras, 1987.

FARIA, L.S.; BERTOLOZZI, M. R. Aproximações teóricas acerca da Vigilância à Saúde: um horizonte para a integralidade. Acta Paulista de Enfermagem, v. 22, n. 4, p. 422-427, 2009.

A vigilância na Atenção Básica à Saúde: perspectivas para o alcance da Vigilância à Saúde. Revista da Escola de Enfermagem da USP, v. 44, n. 3, p. 789-795, 2010.

FOSSAERT, H.; LLOPIS, A.; TIGRE, C. H. Sistemas de vigilância epidemiológica. Boletin de la Oficina Sanitaria Panamericana, v. LXXVI, n. 6, p. 512-524, 1974.

FOUCAULT, M. Microfísica do poder. Rio de Janeiro: Graal, 1979.

. Vigiar e punir. Petrópolis: Vozes, 1987.

FREIRE, P. Educação como prática de liberdade. São Paulo: Paz e Terra, 1977.

. Pedagogia da autonomia - saberes necessários à prática educativa. São Paulo: Paz e Terra, 1996.

GAZZINELLI, M. F. C. et al. Representações de educação em saúde pelos profissionais da equipe de saúde da família. Trabalho, Educação e Saúde, v. 11, n. 3, p. 553-571, 2013.

GEERTZ, C. A interpretação das culturas. Rio de Janeiro: LTC, 2008.

GUIMARÃES, M. B. L. et al. Os impasses da pobreza absoluta: a experiência da Ouvidoria Coletiva da região da Leopoldina, Rio de Janeiro (RJ, Brasil). Ciência \& Saúde Coletiva, v. 16, n. 1, p. 291-300, 2011.

JACINTHO-DA-SILVA, L. Em defesa do território: quarentena e isolamento como medidas de proteção contra a introdução de doenças transmissíveis. In: MIRANDA, A. C. et al. (Org.). Território, ambiente e saúde. Rio de Janeiro: Fiocruz, 2008. p. 77-88.

LANGMUIR, A. D. Evolution of the concept of surveillance in the United States. Proccedings of the Royal Society of Medicine, v. 64, p. 681-684, 1971.

. William Farr: founder of modern concepts of surveillance. International Journal of Epidemiology, v. 5, n. 1, p. 13-18, 1976. 
LARROSA, J. O ensaio e a escrita acadêmica. Educação \& Realidade, v, 28, n. 2, p. 101115, 2003.

LE GOFF, J. A História Nova. In: . (Org.). A História Nova. São Paulo: Martins Fontes, 1990. p. 25-64.

LEITE, J. A.; ASSIS, M. M. A.; CERQUEIRA, E. M. Vigilância epidemiológica no sistema local de saúde. Revista Brasileira de Enfermagem, Brasília (DF), v. 56, n. 2, p. 178-183, 2003. LIMA, C. M. P. et al. A ouvidoria coletiva em Itaboraí. In: LIMA, C. M. (org.). Por uma Itaboraí saudável. Rio de Janeiro: FIOCRUZ, 2011. p. 38-56.

MENDES, E. V. A construção da vigilância à saúde no Distrito Sanitário. In:

(Org.). A vigilância à saúde no distrito sanitário. Série Desenvolvimento de Serviços de Saúde, Brasília, n.10, p. 7-19, Brasília: OPAS, 1993.

MOISÉS, M. Dicionário de Termos Literários. São Paulo: Cultrix, 2004.

MONKEN, M.; BARCELLOS, C. Vigilância em saúde e território utilizado: possibilidades teóricas e metodológicas. Cadernos de Saúde Pública, v. 21, n. 3, p. 898-906, 2005.

MORIN, E. Introdução ao pensamento complexo. Lisboa: Instituto Piaget, 1991.

NATHANSON, N.; LANGMUIR, A. D. The Cutter incident. American Journal of Hygiene, v. 78, p. 16-28, 1963.

OLIVEIRA, R. M.; VALLA, V. V. As condiçôes de vida de grupos populares no Rio de Janeiro: repensando a mobilização poplar no controle do dengue. Cadernos de Saúde Pública, sup. 17 , p. 77-88, 2001.

OMIDIAN, P.; TEHOUNGUE, K.; MONGER, J. Medical anthropology study of the Ebola virus disease (EVD) outbreak in Liberia/West Africa. Monrovia: WHO Representation, 2014. Disponível em: http://www.medbox.org/ebola/medical-anthropology-study-of-the-ebolavirus-disease-evd-outbreak-in-liberiawest-africa/toolboxes/preview

PAIM, J. S.; TEIXEIRA, M. G. L. C. Reorganização do sistema de vigilância epidemiologica na perspectiva do Sistema Único de Saúde. Informe epidemiológico do SUS, v. I, n. 5, p. 25 57, 1972.

RODRIGUES, V. M.; FRACOLLI, L. A.; OLIVEIRA, M. A. C. Possibilidades e limites do trabalho de vigilância epidemiológica no nível local em direção à vigilância à saúde. Revista da Escola de Enfermagem da USP, v. 35, n. 4, p. 313-319, 2001.

ROMERO, A.; TRONCOSO, M. C. La vigilancia epidemiologica: significado e implicaciones en la pratica y en la docencia. Cuadernos Medico Sociales, v. 17, p. 17-28, 1981. SANTOS, M. A natureza do espaço-técnica e tempo, razão e emoção. São Paulo: Hucitec, 1996. SANTOS, S. S. B. S.; MELO, C. M. M. Avaliação da descentralização da vigilância epidemiológica para a equipe de saúde da família. Ciência \& Saúde Coletiva, v. 13, n. 6, p. 1923-1932, 2008. 
SEVALHO, G. Farmacovigilância: bases históricas, conceituais e operacionais. In: GOMES, M. J. V. M. (Org.) Ciências farmacêuticas: uma abordagem em farmácia hospitalar. São Paulo: Atheneu, 2000. p. 109-123.

. Uma abordagem histórica das representações sociais de saúde e doença. Cadernos de Saúde Pública, v. 9, n. 3, p. 349-363, 1993.

SNOW, J. Sobre a maneira de transmissão do cólera. São Paulo: Hucitec, 1990.

SOUSA SANTOS, B. Para além do pensamento abissal: das linhas globais a uma ecologia de saberes. In: SOUSA SANTOS, B.; MENESES, M. P. (orgs). Epistemologias do Sul. São Paulo: Cortez, 2010. p. 31-83.

. Renovar a teoria crítica e reinventar a emancipação social. São Paulo: Boitempo, 2007.

SOUSA SANTOS, B.; MENESES, M. P. (Org.). Epistemologias do Sul. São Paulo: Cortez, 2010.

SOUZA, M. F. M. Et al. Vigilância à saúde: textos. Cadernos CEFOR - Textos, São Paulo, Secretaria Municipal de saúde de São Paulo, v. 2, 1992.

STOTZ, E. Entre a academia e a rua: Victor Vincent Valla (1937-2009). Interface Comunicação, Saúde, Educação, v. 13, n. 31, p. 461-466, 2009.

. Movimentos sociais e saúde: notas para uma discussão. Cadernos de Saúde Pública, v. 10, n. 2, p. 264-268, 1994.

- Trajetória, limites e desafios do controle social do SUS. Saúde em Debate, v. 30, n.73/74, p. 149-160, 2006.

- A educação popular nos movimentos sociais da saúde: uma análise de experiências nas décadas de 1970 e 1980. Trabalho, Educação e Saúde, v. 3, n. 1, p. 9-30, 2005.

TEIXEIRA, C. Promoção e vigilância da saúde no contexto da regionalização da assistência à saúde no SUS. Cadernos de Saúde Pública, v. 18, suplemento, p. 153-162, 2002.

TEIXEIRA, C. F.; PAIM, J. S.; VILASBÔAS, A. L. SUS, modelos assistenciais e vigilância da saúde. Informe Epidemiológico do SUS, v. VII, n. 2, p. 7-34, 1998.

ORGANIZACIÓN MUNDIAL DE LA SALUD. La vigilancia de las enfermedades transmisibles. Cronica de la OMS, v. 22, n. 10, p. 483-489, 1968.

THACKER, S. B.; BERKELMAN, R. L. Public health surveillance in the United States. Epidemiologic Reviews, v. 10, p. 165-190, 1988.

TOGNONI, G. Epidemiologia comunitaria. Apuntes para uma nueva epidemiologia. Salud y Sociedad, v. 20, p. 4-10, 1991.

. Manual de Epidemiologia Comunitária. CECOMET, 1997. Disponível em: http:// www.discograficas.gov.ar/areas/salud/dircap/mat/matbiblio/manual.pdf 
VALLA, V. V. Comentários a "Conselhos Municipais de Saúde: a possibilidade dos usuários participarem e os determinantes da participação”. Ciência e Saúde Coletiva, v. 3, n. 1, p. 31-32, 1998.

Educação popular e conhecimento: a monitoração civil dos serviços de saúde e educação nas metrópoles brasileiras. In: STOTZ, E. N.; VALLA, V. V. (Org.). Participação popular, educação e saúde: teoria e prática. Rio de Janeiro: Relume-Dumará, 1993b. p. 103-112. . A construção desigual do conhecimento e o controle social dos serviços públicos de educação e saúde. In: STOTZ, E. N.; VALLA, V. V. (Org.). Participação popular, educação e saúde: teoria e prática. Rio de Janeiro: Relume-Dumará, 1993a. p. 87-100.

VASCONCELOS, E. M. Introdução - Redefinindo as práticas de saúde a partir da educação popular nos serviços de saúde. In: VASCONCELOS, E. M. (Org.). A saúde nas palavras e nos gestos - reflexões da Rede Educação Popular e Saúde. São Paulo: Hucitec, 2001. p. 11-19. 


\section{Critical notes for the development of Health Civil Surveillance}

The idea and the grounds for health civil surveillance are presented here in a critical essay. This is a proposal developed by Victor Valla in the 1990s, which incorporates the participation of the population into health surveillance through Paulo Freire's popular education. With the resources input from both interpretative anthropology and the new history, a counterpoint is made between the traditional health surveillance, modelled by the epidemiological surveillance, and the health civil surveillance. Remarkable cultural permanencies in the health surveillance practice hegemonically developed in Brazil are then made clear. The prerogative of scientificity, which brings about the subordination to the biomedical clinical model, the political entailment to the idea of social security and the imperative criterion of urgency, characteristics of the traditional health surveillance, block off or raise difficulties to the popular participation. At the end, the health civil surveillance joins the Southern Epistemology by Boaventura de Sousa Santos. The development of health civil surveillance, which incorporates popular participation into health surveillance, meets the proposals historically inscribed in the collective health and conception and evolution of the SUS.

> Key words: health surveillance; health civil surveillance; popular education and health. 